Paidéia, 2001, 11(20), 69-72

\title{
A TRANSFORMAÇÃO DA INFÂNCIA E DA EDUCAÇÃO: ALGUMAS REFLEXÕES SÓCIO-HISTÓRICAS ${ }^{1}$
}

\author{
Catarina Almeida Tomás ${ }^{2}$ \\ Universidade da Beira Interior-Portugal
}

\begin{abstract}
RESUMO: Este artigo tem como objetivo refletir sobre as mudanças sócio-históricas que se produziram na concepção e na vivência da Infância, vinculadas ao papel desempenhado pela Educação, numa análise que procura abranger do período romano à (pós)modernidade. A relação da infância e da educação é vista a partir de uma avaliação das práticas sociais e ideologias dominantes em cada época, pontuando-se as propostas feitas e as realizadas; também se verifica a questão da problematização da situação mundial e discute-se a questão dos Direitos da Infância e da Adolescência, observando o caminho seguido desde a Declaração Universal dos Direitos do Homem, em meados do século XX e, sobretudo salientando as dificuldades na sua implementação em diversos momentos e culturas.
\end{abstract}

Palavras Chave: Infância, Educação, Família, Direitos Humanos

\section{CHILDHOOD AND EDUCATION TRANSFORMATION: SOME SOCIAL-HISTORIC REFLECTIONS}

\begin{abstract}
The objective of this article is to reflect about social-historical changes that happened in the conception of Childhood linked to the role played by Education, with one analysis that follow since the Romam Era until (post)Modernity. The relationship between childhood and education is discussed from an evaluation of social practices and dominant ideologies presents in each period of time, pointing out the propositions and the accomplishments; also it is considered the world situation problematic and it is discussed the question of Children and Adolescents rights, with the observation of the way followed since the Human Rights Universal Declaration, in the end of the $40^{\text {th }}$, but in special emphasizing the difficulties in its implementation in various moments and cultures.
\end{abstract}

Key Words: Childhood, Education, Family, Human Rights

O surgimento cada vez mais generalizado de situaçōes de pobreza, marginalização e exclusão social nas nossas sociedades deve-se, na maioria dos casos, a uma série de promessas que a modernidade não conseguiu cumprir. Tais promessas estavam associadas a um progresso econômico-social que possibilitasse às pessoas uma melhoria da sua qualidade de vida. Mas esse desenvolvimento não se verificou. Não espantará, assim, que o inicio deste novo século se revista de polêmica e controvérsia, sobretudo quando nos referimos à Educação, já que as anunciadas sociedades "educativas" ou "do conhe-

\footnotetext{
${ }^{1}$ Artigo aceito para publicação em outubro de 2001, aceito em abril de 2002.

${ }^{2}$ Endereço para correspondência: Catarina Almeida Tomás, Depto de Sociologia da Universidade da Beira Interior, Estrada do Sineiro, Covilhã, Portugal, Cep.6200, e-mail: ctomas@deimos.ubi.pt
}

cimento" ainda se mantêm na fase da utopia, porque até esta data falhou, particularmente, o compromisso de acolher todas as crianças e proporcionar-lhes uma educação efetiva.

\section{A Educação da Infância: algumas referências his- tóricas}

$\mathrm{Na}$ Roma Antiga os laços sanguíneos eram menos importantes que os vínculos afetivos: a paternidade era antes de tudo uma eleição, o que deu lugar tanto ao abandono como à adoção de crianças passando pela contracepção e o infanticídio, sobretudo dos filhos dos escravos. No direito romano, que durante muitos séculos exerceu uma influência profunda na vida dos povos peninsulares, a família constituiu um núcleo social de caráter essencialmente econômico 
(pobreza e miséria) e político (questão do patrimônio). No império romano o recém-nascido era confiado a uma ama que o amamentava e educava. No caso da educação só os rapazes tinham esse direito até à puberdade, surgindo daí a figura do "pedagogo", também denominado de "amo" (nutritor, tropheus), que tinha como função ensinar-lhes as boas maneiras (Áries, 1960).

Os pais e os professores romanos são conhecidos pela sua extrema severidade ${ }^{3}$, e era função da educação, pelo menos teoricamente, "temperar o caráter enquanto era tempo, para que os indivíduos pudessem resistir, quando adultos, ao micróbio do luxo e da decadência que, por defeito desses tempos, existia em toda a parte" (Ariés \& Duby, 1989:29).

A desigualdade social retrata-se igualmente na educação, pois esta só era acessível às classes altas, isto é, os preceptores privados só existiam apenas para alguns grupos sociais, um dos sexos e nas cidades. Para além destes fatos, "em Roma não se ensinavam matérias formadoras nem utilitárias, mas antes matérias prestigiosas e, acima de tudo, a retórica. Ao longo da história, só excepcionalmente a educação preparará a criança para a vida e será uma imagem da sociedade em ponto pequeno ou em gérmen; freqüentemente, a história da educação é a das idéias existentes sobre a infância e não se explica pela sua função social" (Ariés \& Duby, 1989:32-34).

Pelo contrário, nos séculos II e III d.C. o matrimônio adaptou uma dimensão psicológica e moral, o vínculo e os seus frutos (os filhos) eram considerados sagrados. $\mathrm{E}$ "em meados do século IV os estabelecimentos monásticos recrutavam já muitos jovens. Famílias ricas da cidade ou das aldeias consagravam os filhos ao serviço de Deus; na maior parte das vezes a herança familiar ameaçada por uma prole muito numerosa e, sobretudo, por filhas em excesso" (Ariés \& Duby, 1989:280-281). A educação cristã e todos os códigos morais e de conduta ensinados nos mosteiros, "o paradigma monástico significava o fim do ideal de educação pela cidade" (idem).

Mais tarde, nos séculos X e XI o nascimento de um filho passa a ser considerado uma riqueza indispen-

\footnotetext{
${ }^{3}$ Dizia Séneca que "aos pais forçam o caráter ainda flexível dos bebês a suportar o que lhes fará bem; bem podem chorar e debater-se que não deixarão de os enfaixar estreitamente com medo de que o seu corpo, ainda imaturo, se deforme em vez de crescer direito e, em seguida, de lhes inculcar a cultura liberal, recorrendo ao terror se a recusarem" (Ariés \& Duby, 1989:30)
}

sável e insubstituível; o fato é que os laços de sangue vêm a se constituir no fundamento da ordem sócio-política feudal. E é à mãe que cabe a função da primeira educação, de levar a criança à escola (Berge, 1978).

Na sociedade medieval européia, o sentimento da infância não existia. A criança, a partir dos seis ou sete anos de idade pertencia à sociedade dos adultos, não havendo uma imagem e nem lhe sendo dispensado um tratamento diferenciado. Este fato não parecerá tão estranho, se repararmos que o conceito de família também não é coincidente com o atual vigente. Eram características da família de então: a ausência de uma intimidade, característica importante da dos tempos modernos; a sua estrutura patriarcal configurava-se analogamente a uma monarquia de direito divino. A família era uma unidade de subsistência em que o afeto e os laços sentimentais apareciam como causa de toda a classe de perturbações e as relações entre pais e filhos, baseadas no dever absoluto da obediência, eram fundamentais para a vigência da ordem social da época.

Os historiadores da infância observaram que foi na época pós-medieval que se registraram uma série de mudanças institucionais que irão servir de base à instituição da infância moderna, entendida como um âmbito da vida social, específico e separado do restante. No final do século XVIII, quando já estavam fixadas as bases de uma educação elementar, surgem as primeiras instituições para a educação da infância. A título de exemplo, na Escócia, Robert Owen planejava escolas para as crianças junto das fábricas.

Contudo, importante que se assinale que as mudanças nas atitudes e nas instituições relacionadas com a infância não se desenvolveram de forma isolada ou fortuita; assim, bem pelo contrário, para que sua análise e compreensão se façam de modo adequado há que levar em conta processos sociais mais amplos, de índole econômica, política, histórica, social e cultural (Corsaro, 1997)

A vaga das grandes transformações que marcaram o início da sociedade moderna veio com a Revolução Industrial. Data de então o fato de a família extensa, institucional, centro do universo social em torno do qual toda a vida girava, haver se tornado nuclear. $E$ isso aconteceu porque a família foi perdendo grande parte das funções que, até aí, os respectivos membros desempenhavam como unida- 


\section{A Transformação da Infancia $\mathbf{7 1}$}

de, passando esses a estarem unidos apenas por laços afetivos facilmente quebráveis.

Diversos autores, entre os quais Parsons (1955), apontaram a estreita ligação entre a nuclearização da família e as exigências das sociedades industrializadas. Estas trouxeram uma grande necessidade de mãode-obra, o que gerou um forte movimento migratório no sentido das cidades, onde as indústrias se implementaram. Foi pela transferência das famílias, do campo para a cidade, que se reduziu a sua dimensão, motivada pelas limitações de espaço residenciais, dificuldades econômicas e até restrições laborais à gravidez; por conseguinte, e cada vez mais, o fenômeno pressupôs também fatores de natureza cultural.

A mudança na conduta reprodutiva que teve lugar em alguns países europeus, ainda durante o século XIX, foi, sem dúvida uma das mais transcendentes na história da humanidade. As crianças passaram a representar um valor e uma entidade próprios, o que se deve em grande medida ao fato de o casal poder, em certa medida, ser "livre de decidir ter ou não ter filhos", e em função desse novo objetivo, começar por assumir servir aos filhos, em vez de os utilizar.

É ainda no século XIX que acontece a "educação da infância fora do lar, e ao fazê-lo, descobre e institui a primeira infância, a meninice (do recémnascido aos 3 anos), oscilando entre uma crechitude e as amas de criação. O recurso às amas de criação fora uma prática usual por parte das famílias nobres e burgueses, no decurso do Antigo Regime" (Magalhães, 1997: 120-121).

Assim, a articulação entre a fecundidade e o novo quadro de estruturas mentais surgido da modernidade apresenta-se particularmente importante para entender o objeto analítico do novo campo da infância e da educação.

\section{Direitos Humanos, da Criança, e da Educação}

A História diz-nos que só no século XIX a criança foi objeto do primeiro diploma legal que estabelecia o limite mínimo de idade para o trabalho nas minas de carvão. Foi o Factory Act, na Inglaterra que, como a Bélgica e a França, se mostraram pioneiras nesta matéria. Podemos afirmar que se passou "da descoberta da infância e do seu afastamento do mundo dos adultos, na sociedade como no direito penal (séculos XVI - XVIII), à descoberta da prote- ção à infância (fim do século XIX - XX), à descoberta dos direitos do homem (fim do século XVIII, e, sobretudo, segunda metade do século XX, depois à descoberta dos direitos das crianças e dos jovens (como aplicação dos direitos do homem aos menores, nos últimos 20 anos do século $\mathrm{XX}$ )" (Queloz,1990:55). Embora a ONU (Organização das Nações Unidas) tenha proclamado a Declaração dos Direitos do Homem a 10 de Dezembro de 1948, já em meados do século XX, os temas específicos da Infância não figuravam nela; só em 1959 é que a Assembléia Geral das Nações Unidas promulga a Declaração dos Direitos da Criança.

Contudo, só em meados do século XX, com a adoção pelas Nações Unidas, em 1989, da Convenção Internacional relativa aos Direitos da Criança, a criança passa a ser considerada como cidadão dotado de capacidade para ser titular de direitos.

Apesar da prolifera produção de declarações e convenções, a situação das crianças não melhorou nos últimos. Segundo estimativas da UNICEF, eram apenas necessários 25 mil milhões de dólares anuais para cobrir as necessidades básicas de toda a infância mundial, ou seja, nutrição adequada, água potável, assistência sanitária básica e educação primária ${ }^{4}$.

Desde a Convenção dos Direitos da Criança, em 1989, fica consagrado, de forma clara, um conjunto de direitos fundamentais próprios e inalienáveis; no entanto, essa proclamação não foi suficiente para garantir uma melhoria das condições de existência das crianças. De fato, tem existido muita dificuldade em implementar alguns dos princípios, nomeadamente o direito que a criança tem de receber educação, gratuita e obrigatória (pelo menos nas etapas elementares). E sabido que a realidade social não se transforma por efeito simples da publicação das normas jurídicas (Sebastião, 1998).

Nos países centrais a situação das crianças, que melhorou rapidamente nas últimas décadas, está agora num período de progresso mais lento havendo mesmo casos de retrocesso; observe-se, a título de exemplo, a situação das crianças afegãs que recentemente se tornaram públicos: "Um quarto das crianças afegãs morre antes de completar cinco anos, enquanto que dez por cento sofrem de má nutrição gra-

\footnotetext{
${ }^{4}$ Esta quantidade, 25 milhões de dólares anuais, é 37 vezes inferior aos gastos militares mundiais em 1990, ano a que chegaram a $934 \mathrm{mil} \mathrm{mi-}$ lhões. (UNICEF, 1993:135).
} 


\section{Catarina Almeida Tomás}

ve e 50 por cento de desnutrição crônica" (Lorena, 2001:12). Há que referir ainda que duas gerações de Afegãos são ignorantes, já que o regime talibã só permitia o estudo do Alcorão nas escolas corânicas (Madrassas) e, sobretudo às meninas era vedado o acesso à educação.

Os sucessivos relatórios anuais da UNICEF mostram claramente qual é o processo multiplicador mediante o qual a carga mais pesada da recessão econômica mundial internacional recai, na maioria dos casos, sobre aqueles que têm menos possibilidades de suportá-la. A título de exemplo, nos países em desenvolvimento, mais de $20 \%$ das crianças em idade escolar - cerca de 130 milhões - não vão à escola, e somente a metade das que têm idade para freqüentar o ensino secundário - $55 \%$ de rapazes e perto de $46 \%$ de raparigas - estão realmente matriculados (Unicef, 2000).

Num nível micro, também na família, a pobreza, a falta de espaço, a alimentação insuficiente, o desemprego, o trabalho infantil, o abandono e o insucesso escolar, o alcoolismo, a agressividade e os castigos corporais, assim como a falta de diálogo, o autoritarismo, ou o excesso de permissividade e as rupturas familiares marcam diretamente a vida de uma multidão de crianças.

A Escola, por sua vez, sendo um espaço de filiação e de construção de identidades, de socialização e de diversidade cultural tem um papel primordial na formação das crianças e jovens e, no caso da infância marginalizada, na promoção da sua (re)inserção social, já que a educação é, ou deve ser, um fator de integração e de inclusão, quer ao nível cultural quer ao nível social. Mais ainda, a educação é um direito fundamental das crianças, e importante como fator de transformação dos indivíduos e das sociedades (Tomas, 2000). guido?

O que se indaga é porquê isto não é conse-

Talvez se possa obter resposta ao seguir os argumentos de Guidens (1994) para quem modernidade é uma cultura de risco; para ele, as práticas sociais que se tem hoje introduziram riscos que não foram outrora sentidos pelos nossos antecessores. $\mathrm{O}$ mundo, tal como o conhecemos na atualidade é muito distinto daquele em que viveram as gerações passadas e o tempo e o espaço contemporâneos são conhecedores de no- vas formas de desigualdade, fragmentação e dispersão. (Giddens, 1994).

\section{Referências Bibliográficas}

Ariés, P. (1960). L'Enfance et Ia vie familiale sous l'ancien réqime. Paris: Piou.

Ariès, P. \& Duby, G. (1989). História da Vida Privada. Porto: Edições Afrontamento.

Berge, A. (1978). A Criança. Lisboa: Moraes Editores.

Corsaro, W.A. (1997). The Sociolojzy of Childhood. Thousand Oaks: Pine Forge Press.

Giddens, A. (1994). Modernidade e Identidade Pessoal. Oeiras: Ceita Editora.

Lorena, S.(2001). Em Mazar-i-Sharif todas as noites morrem crianças de fome e frio. Público, (5-12), 12.

Magalhães, J.P. (1997). Um Contributo para a História da Educação da Infância em Portugal. Em M. Pinto \& M.J. Sarmento (Orgs.), As Crianças. Contextos e Identidades (pp. 1 15-145). Braga: Centro de Estudos da Criança/ Universidade do Minho.

Parsons, T. (1955). Family Socialization. New York: Glencoe.

Queloz, N. (1990). Proteção, intervenções e direitos das crianças e dos jovens. Revista Infância e Juventude, 90,(2), 39-59.

Sebastião, J. (1998). Os dilemas da Escolaridade. Universalização, diversidade e inovação. Em Viegas, J. \& Costa, A.F. da (Orgs.). Portugal, que Modernidade? (pp.311-327). Oeiras: Ceita Editora.

Tomás, C. (2000). Ter e Não Deter o Direito de Audição. Estudo de Caso no Colégio de São Fiel. Dissertação de Mestrado, Universidade de Coimbra, Coimbra.

UNICEF. (1993). Informe sobre el estado de Ia infancia. Madrid: UNICEF.

UNICEF. (2000). Hechos y Cifras. 2000. Madrid: UNICEF. 